\title{
Biosensoric potential of microbial fuel cells
}

\author{
György Schneider $^{1}$ (D) Tamás Kovács ${ }^{2} \cdot$ Gábor Rákhely $^{3,4} \cdot$ Miklós Czeller $^{5}$
}

Received: 31 March 2016 /Revised: 20 June 2016 / Accepted: 23 June 2016

(C) Springer-Verlag Berlin Heidelberg 2016

\begin{abstract}
Recent progress in microbial fuel cell (MFC) technology has highlighted the potential of these devices to be used as biosensors. The advantages of MFC-based biosensors are that they are phenotypic and can function in either assayor flow-through formats. These features make them appropriate for contiguous on-line monitoring in laboratories and for in-field applications. The selectivity of an MFC biosensor depends on the applied microorganisms in the anodic compartment where electron transfer (ET) between the artificial surface (anode) and bacterium occurs. This process strongly determines the internal resistance of the sensoric system and thus influences signal outcome and response time. Despite their beneficial characteristics, the number of MFC-based biosensoric applications has been limited until now. The aim of this mini-review is to turn attention to the biosensoric potential of MFCs by summarizing ET mechanisms on which recently established and future sensoric devices are based.
\end{abstract}

The present scientific contribution is dedicated to the 650th anniversary of the foundation of the University of Pécs, Hungary.

György Schneider

gyorgy.schneider@aok.pte.hu

1 Department of Medical Microbiology and Immunology, University of Pécs, Szigeti u. 12, Pécs H 7624, Hungary

2 Department of Biotechnology, Nanophagetherapy Center, Enviroinvest Corporation, Kertváros u. 2, Pécs H 7632, Hungary

3 Department of Biotechnology, University of Szeged, Közép fasor 52, Szeged H 6726, Hungary

4 Institute of Biophysics, Biological Research Center, Hungarian Academy of Sciences, Temesvári krt. 62, Szeged H 6726, Hungary

5 Mediso Medical Imaging Systems, Laborc u. 3, Budapest H 1037, Hungary
Keywords MFC · Biosensor · Electron transfer · Phenotypic · On-line $\cdot$ Diagnostic

\section{Introduction}

Rapid recognition of the presence or effect of toxic compounds is a major challenge in several fields of biology and medicine. Traditional methods have been principally developed for environmental applications and with their help, soil and water samples can be screened for pollutants such as cadmium, arsenic, etc. (Aas et al. 2009). These chemical methods perform adequately in laboratories with special instrumentation, but the application of biosensors, enzymes from living cells or living organisms themselves, offer efficient solutions for toxic compound detection. Traditional procedures apply macroscopic (fish and dapnia) or microscopic (algae and bacteria) organisms (Weyers et al. 2000). Due to several advantageous features, microbes offer promising platforms for biosensing since (i) they are selective: they show a broad spectrum of resistance or sensitivity toward different toxic compounds, (ii) they can metabolize a wide range of chemical compounds, (iii) they are simple to cultivate and are able to thrive under adverse conditions, (iv) they are sensitive to analytes in a highly specific manner, and (v) they are amenable to recombinant DNA technologies (D'Souza 2001). Based on this plasticity, several microbial biosensoric technologies and applications were developed and recently summarized (Dai and Choi 2013). One among them is the microbial fuel cell (MFC)-based technology.

MFCs are electrochemical devices that can convert chemical energy by biological tools into electricity in the presence of organic substrates (Bennetto 1990). MFCs consist of a cathodic and anodic space in double-chamber or single-chamber configuration (Logan et al. 2006). Besides their promising 
large- and small-scale green energy-producing potential, there is growing interest in MFC constructs as biosensoric devices, since it was recently recognized that different small-scale systems are also adequate to assure proper power outputs and current densities (Wang et al. 2011). Due to the emerging interest, several publications have focused on the possibilities of enhancing the sensitivity of MFCs. The key in this process is to minimize the adverse effects of internal resistance and therefore improve the performance and sensitivity of the system (ElMekawy et al. 2013). In order to achieve this, it is important to minimize ohmic losses (ElMekawy et al. 2013) by lowering electrical resistance in the structure and quality of the anodic surface (Scott and Yu 2016). Separators or membranes (Li et al. 2011), electrolyte, and geometrical design (Choi 2015) are also crucial points. On the other hand, it is also crucial to lower non-ohmic losses that originate from the transfer resistance between the biotic and abiotic counterparts of the MFC system and that hinder the direct flow of electrons from the bacteria to the electrode. This is also known as overpotential and has to be conquered with a certain activation overpotential or energy to assure a charge transfer between the two surfaces (Larminie and Dicks 2000).

Formerly, it was thought that, similarly to the classical experiment of Bennetto (1990), electron transfer (ET) by bacteria could only be carried out in the presence of special mediator molecules, but it soon became evident that, at least in the case of some bacteria, this process can also be enforced in the absence of mediators (Allen and Bennetto 1993). A couple of years later, an additional recognition led to the discovery of bacterial surface-associated structures, called nanowires (Reguera et al. 2005). These outer membrane- or pili-based surface structures were found to efficiently transfer electrons directly onto abiotic surfaces and also to other bacteria (Wegener et al. 2015). The advantage of these structures for the bacteria is that they can utilize special environmental niches and create special metabolic circuits. In human terms however, finding of these structures has opened new dimensions for MFC-based biosensoric designs.

Since electron transfer between the biotic and abiotic surface in the anodic compartment is a tipping point for MFCs, in this review, we briefly summarize the known ET mechanisms and demonstrate their potentials for different biosensing purposes by assessing already established and experimental systems.

\section{Basic principle of microbial fuel cells as biosensors}

MFCs are electrochemical devices in which the electricity is generated by the redox metabolic activities of the microorganisms present (Bennetto 1990). Several earlier studies dealt with the operating principles of MFCs and the different designs from large- to small-scales were reviewed (Zhuwei et al.
2007; Choi 2015). If microbes in the anodic chamber are physiologically active and a usable carbon source is available, they generate a potential difference between the anode and cathode that assures a driving force for electron flow. If a toxic compound is present, metabolic pathways in the microbe are influenced that result in reduced or eliminated currentgenerating potential, leading to reduced or eliminated signal strength. This is the feature that qualifies MFCs for biosensoric applications (Chang et al. 2005; Kumlanghan et al. 2007, Kaur et al. 2013), in that microorganisms in the anode compartment act as biocatalysts and the electrodes and proton exchange membrane serve as transducers.

Practical applications of MFC-based biosensors rest on two basic concepts. In the first case, the aim is to detect contaminating microorganisms, thus sterility of a sample can be permanently monitored and revealed. The appearance of a contaminating microorganism induces a positive signal (electron production), while no signal is detected in the case of a sterile sample. In the second case, if a selected bacterium strain is applied as an integral part of the system that is sensitive toward a target chemical, the presence or appearance of this chemical can be monitored. Typical substances with toxic properties to humans include metals, hydrocarbons and their derivatives, pesticides, antibiotics, etc. (Kueh and Lam 2008). Today, the detection of these substances is very complex depending on the substance in question and requires the use of expensive background instruments. For metals, typical methods are ICPMS, atomic absorption spectroscopy (AAS), according to the EN14902 directive of European Committee for Standardization (CEN). Similarly, standard analytical methods were published for the GC, GC-MS, or HPLC analyses of hydrocarbons and their derivatives and numerous artificial compounds (https://www.cen.eu).

Most of these substances derive from industrial activities and pose serious threats to the ecosystems due to their high toxicity and slow or lack of biodegradability. For this reason, early recognition of their appearance is not only crucial to protect complex ecosystems but also to maintain human health. MFC-based biosensoric applications can offer proper solutions to this challenge.

\section{Mechanisms of electron transfer between the bacterium and anode}

The establishment of an electron transfer from the microbial cell to the electrode is a key factor in the proper function of the MFC system. Electrodes are solid entities that cannot penetrate into the cell. Regardless of the mechanism, the bacterial cell somehow has to be linked to the electrode (Schröder 2007). The ancestor of today's MFC was constructed by Potter in 1911 and established that electricity can be liberated by the fermentative activity of yeast and other organisms. 
Already at that time, the different electricity-producing activities of the tested microbes, such as yeast, Bacillus coli communis (today E. coli), Bacillus fluorescens (today Pseudomonas fluorescens), Bacillus violaceus, and Sarcine lutea, were demonstrated. The fact that ET from the microbial cell to the anode can be enhanced was revealed by Bennetto (1990) who applied the dye, methylene blue, as a mediator. At this time, it was already known that electrons gained by the consecutive enzymatic processes of substrate oxidation flow to the respiratory chain.

\section{Mediated electron transfer}

Although microorganisms are not evolutionary designed to power fuel cells, electrons from metabolism can be diverted to a fuel cell anode (Schröder 2007). One possibility for this is the involvement of certain redox molecules with which mediated electron transfer (MET) can be carried out. The most important feature of this process is the presence of proper redox molecules (mediators) that can be readily oxidized and reduced (Fig. 1 (A/1 and A/2)). Mediators assure an indirect linkage and have the capacity to "steal" electrons from the respiratory chain by being reduced; they then shuttle them from the bacterial cell to the anodic surface. Here, mediators pass on the electrons and by being reoxidized, they become ready to complete a new cycle (Bennetto 1990). Bacteria can utilize either artificial (Fig. 1 (A/1)) and/or self produced, natural mediators (Fig. 1 (A/2)).

Methylene blue (Zou et al. 2007), neutral red (Park and Zeikus 2000), thionine (Rahimnejad et al. 2012), methyl orange, bromocresol green, and methyl red (Babanova et al. 2011) are the most studied, exogenously added, or artificial mediators. Their ET-mediating efficacies were revealed in either single species or consortial MFC systems (Park and Zeikus 2000; Taskan et al. 2014) and bacteria with medical relevance, for example, Escherichia coli (Park and Zeikus
2000), Proteus vulgaris (Kim et al. 2000), Klebsiella pneumoniae (Xia et al. 2010; Li et al. 2013), Staphylococcus aureus (Ghanapriya and Kalaichelvan 2012), Pseudomonas aeruginosa (Liu et al. 2012), etc.

At present, use of artificial exogenous redox mediators offers the simplest general mechanism by which ET between the bacterial cell and the artificial anodic surface can be completed. Their general electron-stealing feature is owing to their ability to bind to cytochromes, the ancestral electron transfer molecules of cell membranes with a conserved structural homology among different bacterial species (Schröder 2007).

Certain groups of bacteria are capable of producing their own self-produced natural mediators, and in this way, they can transfer electrons to abiotic surfaces (Fig. 1 (A/2)) without externally added materials. In this process, basically two groups of mediators associated with microbial metabolism can be involved (Madigan et al. 1999). Primary metabolites are major products of catabolic substrate degradation, such as fermentation products and reduced electron acceptors, while secondary metabolites are not usually directly connected to the main metabolite pathways (Hernandez and Newman 2001). Examples for such secondary metabolites that have been shown to be involved in extracellular electron transfer processes are bacterial phenazines, e.g., pyocianine and 2amino-3-carboxyl-1,4-naphtoquinone (Hernandez and Newman 2001). Due to their potential in MFC environments, secondary metabolites are of especially great interest as their synthesis makes ET independent from the presence of exogenous redox shuttles (Schröder 2007). Until now, this advantageous feature seemed to be limited to only some species, e.g., Clostridium butyricum (Park et al. 2001) and Pseudomonas aeruginosa (Rabaey et al. 2005). Very likely, extended studies with recent (Rabaey et al. 2004; Hou et al. 2009; Szöllösi et al. 2015) and new screening methods will contribute to the identification of novel compounds, with proper, self-mediated ET capacities in different microbial species.
Fig. 1 Electron transfer (ET) assuring linkage between the microbial cell and the anodic surface can be mediated and direct. Mediated ET can be performed by using external $(A / 1)$ or internal (self-produced) mediators $(A / 2)$, while close contact $(B / 1)$ and nanowires $(B / 2)$ can assure direct ET (Schröder 2007)

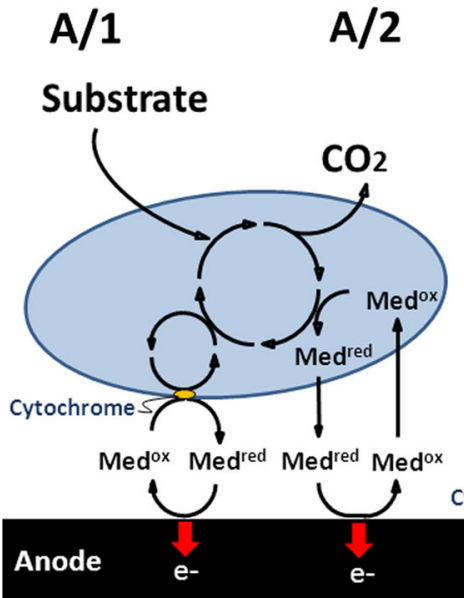

B/1

$B / 2$

\section{Substrate}

\section{Substrate}

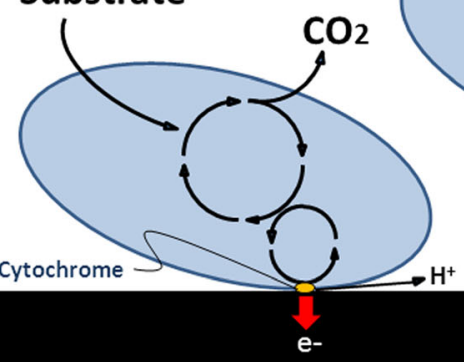

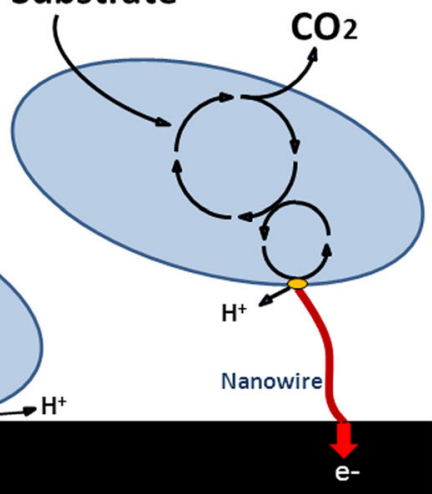




\section{Direct electron transfer}

Self-mediated electron transfer by the bacterial cell is not only accomplished by self-produced mediators but also through direct contact (Fig. $1(\mathrm{~B} / 1$ and $\mathrm{B} / 2)$ ). This kind of ET takes place via a physical contact between the bacterial membrane-associated components and the anodic surface. Since living cells are generally assumed to be electronically non-conducting, such an ET mechanism was long considered impossible, until the experiments of Allen and Bennetto (1993). They demonstrated that in contrast to the free-floating P. vulgaris cells, electric current could be detected if bacteria were chemically immobilized onto a surface of graphite felt electrodes. Since the composition, morphology, and surface quality of MFCs can influence the establishment of direct contact between the bacterial cell and anode, thus having a striking effect on ET, several publications were dedicated to this topic (described as follows). The broad spectra of different metal-, carbon-, and composite-based treated and untreated anode materials were recently summarized (Scott and Yu 2016). A real breakthrough was made when some microbes were found to have the capability of transferring electrons directly to the anode on their own (Kim et al. 1999; Chaudhuri and Lovley 2003). It has been disclosed that in certain groups of bacteria, this efficient direct ET mechanism is associated with fimbria-like surface structures called nanowires (Reguera et al. 2005; Logan 2009). These electrically conductive bacterial appendages have at least two forms. The conductive nanowires of Geobacter sp. are modified pili (Reguera et al. 2005), while in Shewanella sp., they are extensions of the outer membrane (Pirbadian et al. 2014). Their common feature is that they can facilitate long-range ET between the bacterium and abiotic surfaces and also can enhance intercellular and often interspecies electron flow. These nanowires can mediate the electron transfer between oxygen and bacteria staying under anaerobic conditions. Since these structures can also bridge thick biofilm layers, microorganisms possessing these structures can be good candidates for long-term, field screening systems where the biofilm formation of environmental isolates is a problem. Besides their efficient ET abilities, it was recently demonstrated that the outstanding electric potential of these strains can be further enhanced by genetic engineering and in this way, their selectivity and therefore biosensoric potential can be increased for toxic compound detection (Webster et al. 2014).

In order to make the view complete, here, it is also reasonable to mention the experiments of Zhang et al. (2006) who have demonstrated that bacteria could electrochemically evolve in fuel cell environments and by this, they showed significantly enhanced performance.

\section{Recent and future applications of microbial fuel cell-based biosensors}

MFC-based biosensors are ideal for environmental applications since microbes have the tools to sense both the presence and toxicity of chemical species (Belkin 2003). Although there are a number of expensive and time-consuming techniques currently used to detect these agents (Hung et al. 2004; Rong et al. 2007), MFC-based biosensors offer an easy alternative by assuring the possibility of permanent and longterm monitoring.

There are two monitoring system concepts differing in the nature of the applied indicator bacterium.

The basic operating concept of the first monitoring system is based on measuring the activity of the resident flora. In this case, no specific indicator strain is added to the system. The electric signal is the result of the metabolic activity of resident flora with a species composition that is typically unknown. The electric signal deriving from this biomass can be detected until the appearance of a toxic compound or the emergence of a nutrient limitation. Such systems have been published to monitor/detect the biochemical oxygen demand (BOD) during sewage treatment (Changa et al. 2004; Lorenzo et al. 2009; Peixoto et al. 2011; Modin and Wilen 2012), the level of biodegradable organic matter under different conditions (Kumlanghan et al. 2007; Liu et al. 2011; Quek et al. 2015), or the appearance of cadmium in soil (Jiang et al. 2015). The appearance and enrichment of a toxic compound in these monitoring systems metabolically inactivates the existing microflora and is therefore associated with decreased signal intensity. It is probable that electricity production — on which the biosensoric potential is based - in this huge variable microbial mass ET relies on different mechanisms.

The other concept of biosensoric applications is based on monitoring the metabolic activity of a well-determined indicator organism, where the utilized ET mechanism is more specified and depends on the applied bacterium species. Recently, the presence and quantification of arsenic, one of the most common toxic contaminants in water and soil, was reported with such well-defined systems. In one, an Eneterobacter cloaceae strain was used (Rasmussen and Minteer 2015), while in the other, a Shewanella oneidensis strain (Webster et al. 2014) was applied as the indicator organism. Although the goal of both studies was the same, the two solutions substantially differed since one relied on mediated ET with methylene blue as the mediator (Rasmussen and Minteer 2015) while the other was based on direct ET (Webster et al. 2014). There is another major difference between these two systems. Rasmussen and his coworkers designed a system in which metabolic activity, thus electric activity, of the indicator E. cloaceae strain is suppressed in the presence of arsenic, while Webster and his colleagues used a genetically manipulated strain that became electrically active 
if arsenic appeared in the system (Rasmussen and Minteer 2015). Both systems had detection limits for arsenic at around $40 \mu \mathrm{M}$ in water and $100 \mathrm{mg} \mathrm{kg}^{-1}$ in soil.

According to another didactic divison, MFC-based biosensors can be in assay- or flow-through format.

In the assay format, several MFC units are involved in the test system and in each MFC unit, monitoring of the tested samples or bacteria can be carried out. Either an indicator bacterium sensitive for various compounds or a compound affecting various bacteria can be monitored in parallel in these systems. In order to assure their flexibility and broad spectra, a general electron-stealing mechanism is required. Our present knowledge suggests that it can only be fulfilled if MET is utilized by applying a generally accepted mediator, such as methylene blue or other proper dyes. These MFC-based biosensoric applications have promising potential for toxicological screenings of novel drugs on broad spectra of bacterial species in assay format or for testing the effects of several toxic compounds on one or more bacterial species. Recently, a system was evaluated where the presence of specific volatile fatty acid species were detected (Kaur et al. 2013), and a multichannel format was tested where bacterial resistance against different antibiotics could be screened in parallel (Schneider et al. 2015).

Today, flow-through biosensoric systems are successfully used for online monitoring the presence of organic matter (Kumlanghan et al. 2007) or dissolved oxygen in water (Zhang and Angelidaki 2012) and the efficacy of anaerobic digestion processes (Liu et al. 2011). The application of nanowire-possessing bacteria (Logan 2009; Pirbadian et al. 2014; Webster et al. 2014) in flow-through systems is ideal from several reasons. First of all, bacteria become immobilized onto the surface of the anode and direct contact assures ET. The establishment of DET eliminates the need of artificial mediators that are not only expensive but also pose environmental concerns since they have some degree of toxicity. Another crucial point, if long-term environmental monitoring is applied in flow-through formats, is the risk of biofilm formation built by species presenting in the environment. In such systems, the use of indicator strains that can compete with (or even overcome) the biofilm forming capacities of bacteria present in the investigated environmental sample is desirable. If this criteria is not fulfilled, then biofilm forming bacteria in the environmental sample can displace the indicator strain itself and impede long-term monitoring (Janknecht and Melo 2003; Gu 2012). Naturally, this is not a risk in shortterm procedures where there are no time for a massive biofilm formation.

From this point of view, indicator bacteria able to form nanowires and execute DET are ideal in such systems, since these structures also have the capacity to bridge thick biofilm layers. Microorganisms possessing these structures can be good candidates for long-term, in-field screening systems where biofilm formation by environmental isolates is a problem. Besides their efficient ET abilities, these strains can be genetically engineered and so their selectivity and therefore biosensoric potential can be further improved in toxic compound detection (Webster et al. 2014).

A simple trick can also solve the problem caused by biofilm formation in environmental samples. If the indicator microorganism is mesophilic and the anodic chamber, where toxicology tests occur, is kept at a higher temperature (e.g., $37^{\circ} \mathrm{C}$ ), then the biofilm formation capacity of a dominantly psychrophilic environmental bacteria is limited.

Another possibility to hinder biofilm formation was suggested in a recent publication (Yang et al. 2015). The authors revealed that in the investigated microfluidic flow-through MFC system, microchannel geometries have a considerable impact on biofilm distribution and therefore on the performance of the system.

Obviously, biofilm formation certainly is not a risk in those systems where environmental samples are tested in an assay format for a short period of time $(<6 \mathrm{~h})$. The duration of these toxicological investigations does not enable biofilm formation. Therefore, in these biosensoric systems, the application of indicator strains is sufficient, whether ET is based on simple direct contact or utilizes self-produced or artificial mediators.

The previous examples (Table 1) indicate that MFC-based biosensors have a "raison d'etre," but several challenges remain to be solved. Be they portable (Liu et al. 2011) or designed for laboratory conditions (Schneider et al. 2015), one of the most important challenges is their miniaturization and the enhancement of their sensitivity to lower their internal resistance.

\section{Internal resistance in light of electron transfer/miniaturization}

At present, most MFC-based biosensoric systems are middlesized or large-scale monitoring devices (Changa et al. 2004; Kumlanghan et al. 2007; Lorenzo et al. 2009; Quek et al. 2015; Webster et al. 2014; Rasmussen and Minteer 2015; Jiang et al. 2015). One typical feature of these systems is their relatively long response time.

After the appearance of the first experimental microliterscale MFC system (Chiao et al. 2006), several authors focused on the improvement of the characteristics of different microscale devices fabricated with photolithography, etching, polymer molding, and metal deposition, to mention only the most frequently used ones (Kim et al. 2008; Ziaie et al. 2004; Wang et al. 2011).

Attention was turned to the advantages of microsized fuel cells and research was focused to lower internal resistance and, by this, obtain a rapid response time (ElMekawy et al. 2013) and high power density (Choi et al. 2011). 
Table 1 Overview of the different electron transfer mechanisms utilized in recent MFC-based biosensoric applications

\begin{tabular}{|c|c|c|c|c|c|}
\hline $\begin{array}{l}\text { Electron } \\
\text { Transfer }\end{array}$ & Format & Scale & Indicator & Aim & Author \\
\hline Direct & Flow-through & $20 \mathrm{ml}$ & Resident flora & BOD of wastewater & Changa et al. (2004) \\
\hline Direct & Assay & $50 \mathrm{ml}$ & Resident flora & BOD of wastewater & Di Lorenzo et al. (2009) \\
\hline Direct & Flow-through & $9 \mathrm{ml}$ & Mixed flora (sludge) & BOD of wastewater & Peixoto et al. (2011) \\
\hline Direct & $\begin{array}{l}\text { Batch wise } \\
\text { feeding }\end{array}$ & $12 \mathrm{ml}$ & Mixed flora (sludge) & BOD of wastewater & Modin and Wilen (2012) \\
\hline Direct & Flow-through & 2.51 & Resident flora & Organic matter monitoring in wastewater & Kumlanghan et al. (2007) \\
\hline Direct & Assay & $320 \mathrm{ml}$ & $\begin{array}{l}\text { Resident flora } \\
\text { (marine sediment } \\
\text { flora) }\end{array}$ & $\begin{array}{l}\text { Organic matter monitoring in marine } \\
\text { water }\end{array}$ & Quek et al. (2015) \\
\hline Direct & Flow-through & n.a. & E. coli & Dissolved oxygen content & Zhang and Angelidaki (2012) \\
\hline Direct & Flow-through & $1.6 \mathrm{ml}$ & Mixed flora (sludge) & Anaerobic digestion potential & Liu et al. (2011) \\
\hline Direct & Assay & $200 \mathrm{ml}$ & Resident flora (soil) & Cadmium detection in soil & Jiang et al. (2015) \\
\hline Direct & Assay & n.a. & Enterobacter cloaceae & Arsenic detection & $\begin{array}{l}\text { Rasmussen and Minteer } \\
\text { (2015) }\end{array}$ \\
\hline Direct & Flow-through & n.a. & Shewanella oneidensis & Arsenic detection & Webster et al. (2014) \\
\hline Direct & Assay & $250 \mathrm{ml}$ & Mixed flora (sludge) & Volatile fatty acids & Kaur et al. (2013) \\
\hline Mediated & Assay & $250 \mu 1$ & E. coli and S. aureus & Antibiogram determination & Schneider et al. (2015) \\
\hline
\end{tabular}

Performance and reaction time in MFC systems depends on the internal resistance, which can be ohmic and non-ohmic, and has been shown to limit the power output of the microbial fuel cells in middle-sized applications (Liang et al. 2007).

Ohmic losses are due to the electrical resistance of the electrodes, membrane, and electrolyte, while non-ohmic losses are associated with preceding chemical or biochemical reactions (Bard and Faulkner 2001) and electron transfer resistance between the bacterial cell and the anode (Larminie and Dicks 2000).

Since electrochemical reactions on MFC electrode surfaces require a certain activation energy for electron transfer, middle- and large-scale systems are characterized by a considerable lag period after inoculation. Its duration is dependent on the efficacy of cell-anode coupling that, however, depends on the counterparts of the applied system: the bacterium, mediator (if present), and anode. Activation energy can be partially compensated by applying highly conductive anodic materials. Stainless steel (Dumas et al. 2008; Ouitrakul et al. 2007), titanium (ter Heijne et al. 2008), nickel (Ouitrakul et al. 2007), gold (Hou et al. 2009), etc. can be potential anodic materials even in microscale systems. Contrarily, copper was shown to be unsuitable as an anode due to its toxicity for microorganisms (Kargi and Eker 2007; Zhu and Logan 2014). A very detailed summary of the hitherto applied anodic materials was recently published (Scott and Yu 2016). Due to its very good conductivity and adaptability into microscale systems, gold was successfully used, but most authors turned to carbon-based anodic surfaces since they can be versatile and have organic nature that can promote ET between the biotic and abiotic partners in the anodic chamber. Carbon cloth (Qian et al. 2009), carbon paper and felt (Park et al. 2011), graphite-covered printed circuit board (PCB) panels (Schneider et al. 2015), and graphite integrated into a microfluidic system (Ye et al. 2013) were recently used for these purposes. Although it was revealed that different forms of carbon-based electrodes improve coupling (Bond et al. 2002; Chaudhuri and Lovley 2003; Logan et al. 2007), simple pretreatment could highly increase ET (Wang et al. 2009). Surface treatment with ammonia applied by the authors proved to be effective, likely facilitating bacterial adhesion and thus increasing ET (DET).

Not only the modification of chemical composition but also its structure can have a great impact on system efficacy. For this enhancement of the electrode, surface area/volume ratio (SAV) is required. Anodes with microstructures or surface coatings not only increase the surface area for current collecting but also improve the coupling ability of microbes to the electrode surface (Crittenden et al. 2006; Siu and Chiao 2008).

In several cases, the ideal MFC-based biosensor is a microscale one. Qian et al. (2009) have demonstrated that in such systems, current generation was rapid upon inoculation. Similarly to other groups, they used carbon cloth as the anode, but the fast reaction was most likely the consequence of the high bacterial cell number and the short distance between the electrodes. This latter one efficiently decreases ohmic resistance and capacitates the system to be more responsive to the electrochemical change in the anodic chamber (Qian et al. 2011). This observation was a strong feedback that in order 
to gain efficient current collection, the anodic space ideally has to be flattened and a relatively large surface area has to be provided in order to promote efficient electron transfer between the bacterial cell and anodic surface.

\section{Conclusion}

The concept of the MFCs has been validated by macroscopic devices during the last decade and a half. Due to their plasticity, MFCs can also be applied for sensoric purposes. Scaling them down revealed their advantageous characteristics. These systems can be adapted to various bacteria and different ET mechanisms depending on the intended purpose of these devices. DET is preferable in flow-through systems, while DET based on the application of mediators can be ideally used in laboratory assays. Development of microsized MFC systems offers great opportunities for biosensoric applications not only for in-field but also for diagnostic and research purposes.

Acknowledgments The present work was partly supported by the Hungarian Government (MFCDiagn-TECH_08-A1-2008-0279) and the University of Pécs: PTE ÁOK-KA-2013/23.

\section{Compliance with ethical standards}

Conflict of interest The authors declare that they have no conflict of interest.

Ethical statement This article does not contain any studies with human participants or animals performed by any of the authors.

\section{References}

Aas W, Alleman LY, Bieber E, Gladtke HJ-L, Vuokko Karlsson V, Christian Monies C (2009) Comparison of methods for measuring atmospheric deposition of arsenic, cadmium, nickel and lead. J Environ Monit 11:1276-1283

Allen RM, Bennetto HP (1993) Microbial fuel-cells: electricity production of carbohydrates. Appl Biochem Biotechnol 39-40:27-40

Babanova S, Hubenova Y, Mitov M (2011) Influence of artificial mediators on yeast-based fuel cell performance. J Biosci Bioeng 112(4): 379-387

Bard AJ, Faulkner LR (2001) Electrochemical methods: fundamentals and applications, 2nd edn. Wiley, New York

Belkin S (2003) Microbial whole-cell sensing systems of environmental pollutants. Curr Opin Microbiol 6(3):206-212

Bennetto HP (1990) Electricity generation by micro-organisms. Biotechnol Educ 1(4):163-168

Bond DR, Holmes DE, Tender LM, Lovley DR (2002) Electrodereducing microorganisms that harvest energy from marine sediments. Science 295(5554):483-485

Chang S, Moon H, Jang JK, Kim BH (2005) Improvement of a microbial fuel cell performance as a BOD sensor using respiratory inhibitors. Biosens Bioelectron 20(9):1856-1859
Changa IS, Janga JK, Gila GC, Kima M, Kima HY, Chob BW, Kim BH (2004) Continuous determination of biochemical oxygen demand using microbial fuel cell type biosensor. Biosens Bioelectron 19: 607-613

Chaudhuri SK, Lovley DR (2003) Electricity generation by direct oxidation of glucose in mediatorless microbial fuel cells. Nat Biotechnol 21(10):1229-1232

Chiao M, Lam KB, Lin LW (2006) Micromachined microbial and photosynthetic fuel cells. J Micromech Microeng 16(12):2547-2553

Choi S (2015) Microscale microbial fuel cells: advances and challenges. Biosens Bioelectron 69:8-25

Choi S, Lee HS, Yang Y, Parameswaran P, Torres CI, Rittmann BE, Chae $\mathrm{J}$ (2011) A $\mu \mathrm{L}$-scale micromachined microbial fuel cell having high power density. Lab Chip 11(6):1110-1117

Crittenden SR, Sund CJ, Summer JJ (2006) Mediated electron transfer from bacteria to a gold electrode via self-assembled monolayer. Langmuir 22(23):9473-9476

Dai C, Choi S (2013) Technology and applications of microbial biosensors. Open J Appl Biosens 2:83-93

D'Souza SF (2001) Microbial biosensors. Biosens Bioelectron 16(6): $337-353$

Dumas C, Mollica A, Féron D, Basséguy R, Etcheverry L, Bergel A (2008) Marine microbial fuel cell: use of stainless steel electrodes as anode and cathode materials. Electrochim Acta 53(2):468-473

ElMekawy A, Hegab HM, Benetton XD, Pant D (2013) Internal resistance of microfluidic microbial fuel cell: challenges and potential opportunities. Bioresour Technol 142:672-682

Ghanapriya K, Kalaichelvan PT (2012) Electricity generation from bacteria Staphylococcus aureus and Enterobacteriaceae bacterium using microbial fuel cell - an alternative source of energy and its use application. Int J Curr Sci:87-93

Gu T (2012) Methods and devices for the detection of biofilms. World Intellectual Property Organization: Patent WO2012/149487

Hernandez ME, Newman DK (2001) Extracellular electrontransfer. Cell Mol Life Sci 58:1562-1571

Hou HJ, Li L, Cho Y, de Figueiredo P, Han A (2009) Microfabricated microbial fuel cell arrays reveal electrochemically active microbes. PLoS One 4(8):e6570

Hung DQ, Nekrassova O, Compton RG (2004) Analytical methods for inorganic arsenic in water: a review. Talanta 64:269-277

Janknecht P, Melo LF (2003) Online biofilm monitoring. Rev Environ Sci Biotechnol 2:269-283

Jiang YB, Denga H, Sunb DM, Zhong WH (2015) Electrical signals generated by soil microorganisms in microbial fuel cells respond linearly to soil $\mathrm{Cd}^{2+}$ pollution. Geoderma 255-256:35-41

Kargi F, Eker S (2007) Electricity generation with simultaneous wastewater treatment by a microbial fuel cell (MFC) with $\mathrm{Cu}$ and $\mathrm{Cu}-\mathrm{Au}$ electrodes. J Chem Technol Biotechnol 82(7):658-662

Kaur A, Kim JR, Michie I, Dinsdale RM, Guwy AJ, Premier GC (2013) Microbial fuel cell type biosensor for specific volatile fatty acids using acclimated bacterial communities. Biosens Bioelectron 47: $50-55$

Kim BH, Kim HJ, Hyun MS, Park DH (1999) Direct electrode reaction of Fe (III)-reducing bacterium, Shewanella putrifaciens. J Microbiol Biotechnol 9:127-131

Kim N, Choi Y, Jung S, Kim S (2000) Effect of initial carbon sources on the performance of microbial fuel cells containing Proteus vulgaris. Biotechnol Bioeng 70(1):109-114

Kim P, Kwon KW, Park MC, Lee SH, Kim SM, Suh KY (2008) Soft lithography for microfluidics: a review. Biochip J 2(1):1-11

Kueh CSW, Lam JYC (2008) Monitoring of toxic substances in the Hong Kong marine environment. Mar Pollut Bull 57:744-757

Kumlanghan A, Liu J, Thavarungkul P, Kanatharana P, Mattiasson B (2007) Microbial fuel cell-based biosensor for fast analysis of biodegradable organic matter. Biosens Bioelectron 22:2939-2944 
Larminie J, Dicks A (2000) Fuel cell systems explained. Wiley, Chichester, p. 308

Li WW, Sheng GP, Liu XW, Yu HQ (2011) Recent advances in the separators for microbial fuel cells. Bioresour Technol 102:244-252

Li X, Liu L, Liu T, Yuan T, Zhang W, Li F, Zhou S, Li Y (2013) Electron transfer capacity dependence of quinone-mediated $\mathrm{Fe}(\mathrm{III})$ reduction and current generation by Klebsiella pneumoniae L17. Chemosphere 92(2):218-224

Liang P, Huang X, Fan MZ, Cao XX, Wang C (2007) Composition and distribution of internal resistance in three types of microbial fuel cells. Appl Microbiol Biotechnol 77(3):551-558

Liu J, Qiao Y, Guo CX, Lim S, Song H, Li CM (2012) Graphene/carbon cloth anode for high-performance mediatorless microbial fuel cells. Bioresour Technol 114:275-280

Liu Z, Liu J, Zhang S, Xing XH, Su Z (2011) Microbial fuel cell based biosensor for in situ monitoring of anaerobic digestion process. Bioresour Technol 102(22):10221-10229

Logan BE, Hamelers B, Rozendal R, Schroder U, Keller J, Freguia S, Aelterman P, Verstraete W, Rabaey K (2006) Microbial fuel cells: methodology and technology. Environ Sci Technol 40:5181-5192

Logan B, Cheng S, Watson V, Estadt G (2007) Graphite fiber brush anodes for increased power production in air-cathode microbial fuel cells. Environ Sci Technol 41(9):3341-3346

Logan B (2009) Exoelectrogenic bacteria that power microbial fuel cells. Nat Rev Microbiol 7:375-381

Lorenzo MD, Curtisa TP, Heada IM, Scott K (2009) A single-chamber microbial fuel cell as a biosensor for wastewaters. Water Res 43: 3145-3154

Madigan MT, Martink JM, Parker J (1999) Brock biology of microorganisms, 8th edn. Prentice Hall International, Inc., Upper Saddle River

Modin O, Wilen B (2012) A novel bioelectrochemical BOD sensor operating with voltage input. Water Res 46(18):6113-6120

Ouitrakul S, Sriyudthsak M, Charojrochkul S, Kakizono T (2007) Impedance analysis of bio-fuel cell electrodes. Biosens Bioelectron 23(5):721-727

Park DH, Zeikus JG (2000) Electricity generation in microbial fuel cells using neutral red as an electronophore. Appl Environ Microbiol 66(4):1292-1295

Park HS, Kim BH, Kim HS, Kim HJ, Kim GJ, Kim M, Chang IS, Park YK, Chang HI (2001) A novel electrochemically active and Fe(III)reducing bacterium phylogenetically related to Clostridium butyricum isolated from a microbial fuel cell. Anaerobe 7:297-306

Park IH, Gnana KG, Kim AR, Kim P, Suk NK (2011) Microbial electricity generation of diversified carbonaceous electrodes under variable mediators. Bioelectrochemistry 80:99-104

Peixoto L, Min B, Martins G, Brito AG, Kroff P, Parpot I, Angelidaki I, Nogueira R (2011) In situ microbial fuel cell-based biosensor for organic carbon. Bioelectrochemistry 81(2):99-103

Pirbadian S, Barchinger SE, Leung KM, Byun HS, Jangir Y, Bouhenni RA, Reed SB, Romine MF, Saffarini DA, Shi L, Gorby YA, Golbeck JH, El-Naggar MY (2014) Shewanella oneidensis MR-1 are outer membrane and periplasmic extensions of the extracellular electron transport components. Biophys J 111(35):12883-12888

Potter MC (1911) Electrical effects accompanying the decomposition of organic compounds. Proc R Soc London, Ser B 84:260-276

Qian F, Baum M, Gu Q, Morse DE (2009) A $1.5 \mu \mathrm{L}$ microbial fuel cell for on-chip bioelectricity generation. Lab Chip 9(21):3076-3081

Qian F, He Z, Thelen MP, Li Y (2011) A microfluidic microbial fuel cell fabricated by soft lithography. Bioresour Technol 102(10):5836-5840

Quek SB, Cheng L, Cord-Ruwisch R (2015) Microbial fuel cell biosensor for rapid assessment of assimilable organic carbon under marine conditions. Water Res 77:64-71

Rabaey K, Boon N, Siciliano SD, Verhaege M, Verstraete W (2004) Biofuel cells select for microbial consortia that self-mediate electron transfer. Appl Environ Microbiol 70(9):5373-5382
Rabaey K, Boon N, Höfte M, Verstraete W (2005) Microbial phenazine production enhances electron transfer in biofuel cells. Environ Sci Technol 39(9):3401-3408

Rahimnejad M, Najafpour GD, Ghoreyshi AA, Talebnia F, Premier GC, Bakeri G, Kim JR, Oh SE (2012) Thionine increases electricity generation from microbial fuel cell using Saccharomyces cerevisiae and exoelectrogenic mixed culture. J Microbiol 50(4):575-580

Rasmussen M, Minteer SD (2015) Long-term arsenic monitoring with an Enterobacter cloacae microbial fuel cell. Bioelectrochemistry 106: 207-212

Reguera G, McCarthy KD, Mehta T, Nicoll JS, Tuominen MT, Lovley DR (2005) Extracellular electron transfer via microbial nanowires. Nature 435(7045):1098-1101

Rong XM, Huang QY, Jiang DH, Cai P, Liang W (2007) Isothermalmicrocalorimetry: a review of applications in soil and environmental sciences. Pedosphere 17:137-145

Schneider G, Czeller M, Rostás V, Kovács T (2015) Microbial fuel cellbased diagnostic platform to reveal antibacterial effect of betalactam antibiotics. Enzym Microb Technol 73-74:59-64

Scott K, Yu EH (2016) Microbial electrochemical and fuel cells: fundamentals and applications. Woodhead Publishing Series in Energy: Number 88., Woodhead Publishing Ltd

Schröder U (2007) Anodic electron transfer mechanisms in microbial fuel cells and their energy efficiency. Phys Chem Chem Phys 9(21): 2619-2629

Siu CPB, Chiao M (2008) A microfabricated PDMS microbial fuel cell. J Microelectromech Syst 17(6):1329-1341

Szöllősi A, Rezessy-Szabó JM, Hoschke Á, Nguyen QD (2015) Novel method for screening microbes for application in microbial fuel cell. Bioresour Technol 179:123-127

Taskan E, Özkaya B, Hasar H (2014) Effect of different mediator concentrations on power generation in MFC using Ti-TiO2. Electron Int J Energy Sci 4:334-497

ter Heijne A, Hamelers HVM, Saakes M, Buisman CJN (2008) Performance of non-porous graphite and titanium-based anodes in microbial fuel cells. Electrochim Acta 53(18):5697-5703

Wang X, Cheng S, Feng Y, Merrill MD, Saito T, Logan BE (2009) Use of carbon mesh anodes and the effect of different pretreatment methods on power production in microbial fuel cells. Environ Sci Technol 43(17):6870-6874

Wang HY, Bernarda A, Huang CH, Lee DJ, Chang JS (2011) Micro-sized microbial fuel cell: a mini-review. Bioresour Technol 102(1):235-243

Webster DP, TerAvest MA, Doud DFR, Chakravorty A, Holmes EC, Radens CM, Sureka S, Gralnick JA, Angenent LT (2014) An arsenic-specific biosensor with genetically engineered Shewanella oneidensis in a bioelectrochemical system. Biosens Bioelectron 62: 320-324

Wegener G, Krukenberg V, Riedel D, Tegetmeyer HE, Boetius A (2015) Intercellular wiring enables electron transfer between methanotrophic archaea and bacteria. Nature 526:587-590

Weyers A, Sokull-Kluttgen B, Baraibar-Fentanes J, Vollmer G (2000) Acute toxicity data: a comprehensive comparison of results of fish, Daphnia, and algae tests with new substances notified in the European Union. Environ Toxicol Chem 19:1931-1933

Xia X, Cao XX, Liang P, Huang X, Yang SP, Zhao GG (2010) Electricity generation from glucose by a Klebsiella sp. in microbial fuel cells. Appl Microbiol Biotechnol 87(1):383-390

Yang Y, Ye D, Li J, Zhu X, Liao Q, Zhang B (2015) Biofilm distribution and performance of microfluidic microbial fuel cells with different microchannel geometries. Int J Hydrog Energy 40(35):11983-11988

Ye D, Yang Y, Li J, Zhu X, Liao Q, Deng B, Chen R (2013) Performance of a microfluidic microbial fuel cell based on graphite electrodes. Int J Hydrog Energy 38(35):15710-15715

Zhang Y, Angelidaki I (2012) A simple and rapid method for monitoring dissolved oxygen in water with a submersible microbial fuel cell (SBMFC). Biosens Bioelectron 38:189-194 
Zhang T, Cui C, Chen S, Ai X, Yang H, Shen P, Peng Z (2006) A novel mediatorless microbial fuel cell based on direct biocatalysis of Escherichia coli. Chem Commun 21:2257-2259

Zhuwei D, Haoran L, Tingyue G (2007) A state of the art review on microbial fuel cells: a promising technology for wastewater treatment and bioenergy. Biotechnol Adv 25:464-482

Zhu X, Logan BE (2014) Copper anode corrosion affects power generation in microbial fuel cells. J Chem Technol Biotechnol 89(3):471-474
Ziaie B, Baldi A, Lei M, Gu YD, Siegel RA (2004) Hard and soft micromachining for BioMEMS: review of techniques and examples of applications in microfluidics and drug delivery. Adv Drug Deliv Rev 56(2):145-172

Zou YJ, Sun LX, Xu F, Yang LN (2007) E. coli microbial fuel cell using new methylene blue as electron mediator. Chem J Chin Univ 28: $510-513$ 